\title{
Metastasis of Thyroid Adenocarcinoma in Mandible
}

Ana Carolina Loureiro ${ }^{1}$, Cláudia Figueiredo², Jefferson David Melo de Matos ${ }^{3}$, Rafaela Vasconcelos de Melo Lima ${ }^{4}$, Ricardo Barreto Almeida Vasconcelos $^{4}$, Gilberto de Alencar Nunes ${ }^{5}$, Jéferson Martins Pereira Lucena Franco ${ }^{6}$, Mauricio Antonio dos Santos ${ }^{7}$, Bruna Caroline Gonçalves de Vaconce$\operatorname{los}^{8}$, Tiago Norões Gomes 9 , Victor ArchetiVardiero 9 , John Eversong Lucena de Vasconcelos ${ }^{9}$, Viviane Maria Gonçalves de Figueiredo ${ }^{10^{*}}$

${ }^{1}$ Professor Master, Departament of Dentistry, Centro Universitário de João Pessoa UNIPÊ - Joao Pessoa - PB, Brasil.

${ }^{2}$ Professor Doctor - Oral Pathologist, Department of Dentistry, Universidade Federal da Paraíba UFPB, Joao Pessoa - PB, Brasil.

${ }^{3}$ School of Dentistry, Centro Universitário UNILEÃO, Juazeiro do Norte, Ceará, Brasil.

${ }^{4}$ School of Dentistry, Faculdade Mauricio de Nassau, Recife, Pernambuco, Brasil.

${ }^{5}$ Specialist in Pathological Anatomy and Surgical Pathology at AC Camaro Cancer Hospital, São Paulo - SP.

${ }^{6}$ School of Dentistry, Department of Oral and Maxillofacial Surgery, Centro Caririense de Pós-Graduação CECAP, Juazeiro do Norte, Ceará, Brasil.

${ }^{7}$ Department of Languages and Literatures, Regional University of Cariri, Crato, Ceará, Brazil.

${ }^{8}$ Master's Degree of Orthodontics, San LeopoldoMandic, Campinas - São Paulo.

${ }^{9}$ Professor de Implante, Departamento de Odontologia, Centro Caririense de Pós-Graduação CECAP, Juazeiro do Norte, Ceará, Brasil.

${ }^{10}$ Professor of Dental Prosthetics, Department of Dentistry, Centro Universitário UNILEÃO, Juazeiro do Norte - CE.

\section{Abstract}

Introduction: Thyroid carcinoma is a malignant neoplasia associated with radiation exposure, which is a risk factor for the disease, which induces cell mutation of that gland.

Objective: On the basis of the above, the objective of this work is to present a clinical case of a patient whosought the Stomatology Service of the Federal University of Paraíba, complaining of swelling in the mandibular region.

Case Report: Patient JMC, a 54-year old woman, melanoderma, sought the Stomatology Service of UFPB, bearing apanoramic radiography and reportings welling in the region of the body, on the left branch of the mandible, and the presence of local painful symptoms. The patient reported thyroid nodule removal two years ago. The clinical examination showed that the lesion presented exophytic growth and firm consistency, numerous diagnostic measures were performed, however, the only that provided the best results and accuracy of diagnosis was the biopsy. But as the diagnosis was very late, she came to death even before the completion of the usual surgical management.

Conclusion: The diagnosis of primary and metastatic malignant gnathic bone neoplasms is primarily made on anamnesis, clinical, laboratorial, radiological, and histopathological data; thus being a multidisciplinary work.

Keywords: Adenocarcinoma; Mandible; Metastic Neoplasm; Thyroid.

\section{Introduction}

The bone metastases in the oral cavity are extremely rare, they represent $1-3 \%$ of all oral malignant neoplasms. When they attack the complex maxillomandibular, $80-90 \%$ of cases are located in the mandible, showing symptoms similar to odontogenic infections and benign tumors [1].
Among tumors that present metastasis in jaw; lung, breast, adrenals, kidneys, bones, rectum and prostate are more frequent, being the breast and the lung carcinomas of a higher incidence. Metastasis of tumors of intestine, thyroid, esophagus, liver and uterus were also reported [2].

\section{*Corresponding Author:}

Viviane Maria Gonçalves de Figueiredo,

Professora de Prótese Dentária, Departamento de Odontologia, Centro Universitário UNILEÃO,

Clínica Escola: Rua Ricardo Luiz de Andrade, 311 Planalto - Juazeiro do Norte - CE - CEP 63047-310.

E-mail: vivi_mfigueiredo@yahoo.com.br

Received: January 31, 2017

Accepted: March 15, 2017

Published: March 17, 2017

Citation: Ana Carolina Loureiro, Cláudia Figueiredo, Jefferson David Melo de Matos, Rafaela Vasconcelos de Melo Lima, Viviane Maria Gonçalves de Figueiredo, et al., (2017) Metastasis of Thyroid Adenocarcinoma in Mandible. Int J Dentistry Oral Sci. 4(3), 439-443. doi: http://dx.doi.org/10.19070/2377-8075-1700087

Copyright: Viviane Maria Gonçalves de Figueiredo ${ }^{\circ}$ 2017. This is an open-access article distributed under the terms of the Creative Commons Attribution License, which permits unrestricted use, distribution and reproduction in any medium, provided the original author and source are credited. 
In one third of patients with metastasis in oral tissue, the metastatic lesion represents the first evidence of metastases from primary site. The diagnosis of primary and metastatic malignant gnathic bone neoplasms is primarily made on a clinical anamnesis, laboratorial, radiological and histopathological data. The diagnosis of those neoplasms can, however, offer difficulties with regard to their differential aspects [3].

Thyroid tumors are subdivided into follicular adenoma of thyroid, follicular thyroid carcinoma, and papillary thyroid carcinoma. The transformation of a well-differentiated thyroid carcinoma (papillary or follicular) to an undifferentiated is a rare event that occurs in about $1-2 \%$ of cases. Papillar is the most common cancer of the thyroid; it can usually get introduced, initially, as lump [4].

Thyroid carcinoma is a malignant neoplasia associated to radiation exposure, which is a risk factor for the disease that induces cellular mutation of this gland. Distant metastasis of differentiated thyroid carcinomas occurs in $10-15 \%$ of patients with the disease. Regarding the gnathic bones, there is a prevalence of cases in mandible and only one case was reported in the maxilla. All age groups are affected [5].

The follicular is the most frequent histological type in literature. There is evidence of edema, pain, high vascularization of the bone lesion, dental losses, lip and chin paresthesia, symptom that means bone tumor invasion and the commitment of the inferior dental nerve and mental nerve [6].

The prognosis of gnathic bones metastatic neoplasms is considered reserved and somber, as a result of the pathophysiology of primary tumor that originated the metastasis, which usually presents with a high degree of histological aggression, occur in an advanced stage of the disease and because of the existence of paraneoplastic syndromes associated to it. The diagnosis is delayed and challenging because of the difficulty in relation to differential aspects of the disease, being made on anamnesis, clinical, laboratorial, radiological, and histopathological data [7].

Hemithyroidectomy is a favorable therapy to that tumour control, it reduces surgical complications and the patients are spared of therapy with iodine; the treatment is still multidisciplinary and the prognosis is considered reserved and somber, as a result of the high degree of histological aggressiveness of primary tumor, and advanced stage of the disease [8].

The present study aims to present a clinical case of metastasis of thyroid adenocarcinoma in mandible, describing the most important aspects and the major controversies.

\section{Case Report}

Patient JMC, a 54-year old woman, melanoderma, sought the Stomatology Service of UFPB, reporting tumefaction in the region of the body, and on the left branch of the mandible, and the presence of local painful symptoms (Figure 01). The patientreported removal of thyroid nodule two years ago. At clinical examination, the lesion presented exophitic growth and firm consistency.

In the radiographic examination, it was found bone fenestration, bicortical expansion of body and branch of mandible, ill-defined margins featuring the presence of metastasis, discreet expansion of lingual and vestibular cortical areas, reabsorption accented with severe destruction of cortical bone on the right side, hyperdense or hypernatural images (Figure 02).

Initially, it was opted for doing the puncture aspiration in order

Figure 1. Aspect of Lesion in Intraoral Region.

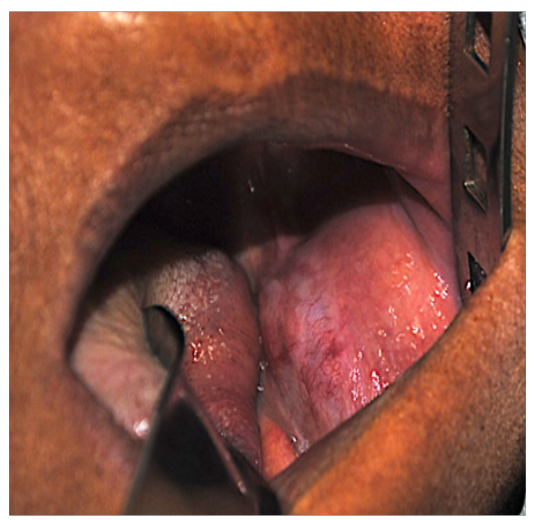

Figure 2. Computerized Tomography in Frontal and Lateral View.
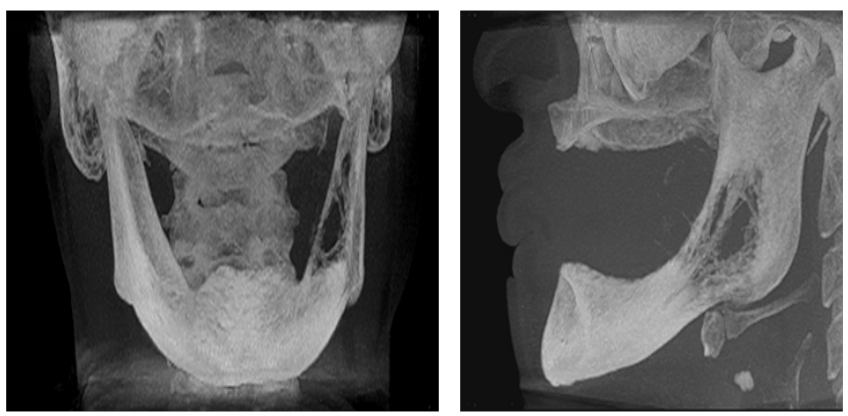
to aid in clinical diagnosis, making sure, which pathological condition was being treated, and still enriching the diagnosis which would be proposed. The material collected during the puncture had hematopoietic aspect, with no evidence of the presence of fat or mucous material. The cytology was inconclusive, showing only hematopoietic cells (Figure 03).

The patient presented expansion of two cortical in the region of the body, radiographically, the lesions are undefined and may be presented asosteolytic or radiolucent, with ill-defined margins that in metastases of breast, lung and prostate, may present sclerotic aspect, they may also present hyper or mixed osteoblastic appearance.

Based on the clinical and radiographic findings, it was proposed the realization of incisional biopsy, in which two fragments were extracted. During biopsy the patient suffered bleeding and was hospitalized (Figure 04). Macroscopically the material obtained was soft, white with brownish spots, irregular shape and surface, fibrous consistency, measuring $1.0 \mathrm{x} 1.0,1.0 \mathrm{x} 0.5 \mathrm{~cm}$ and $1.0 \mathrm{x} 0.5$, $0.5 \times 0.5 \mathrm{~cm}$. The largest fragment was sectioned and presented the same macroscopic characteristics already mentioned.

The histopathological examination demonstrates neoplastic cells arranged in irregular multiple follicles infiltrating dense stroma. The follicles present eosinophilic material compatible with colloid (Figure 05, 06 and 07). The histopathological diagnosis was suggestive of metastatic follicular adenocarcinoma, with probable origin in thyroid, the discussion with another pathologist suggested possibility of papillary thyroid carcinoma.

Six years ago the patient had sought the Endocrinology Service of University Hospital Lauro Wanderley, João Pessoa - PB, reporting the presence of anterior cervical volume increase, with progressive growth over the past four years, a feeling of suffocation when in decubitus and with no suggestive complaints of hyperthyroidism and hypothyroidism. She did not report presence of a family history for thyroidopaties.

The ultrasonography showed mixed nodule of regular outlines, measuring $4.1 \times 3.3 \mathrm{~cm}$ in the left lobe. Normal TSH. Fine-needle aspiration cytology (FNAC) diagnosed colloid nodular goiter. Partial thyroidectomy was made; the material collected was submitted to biopsy, with clinical diagnosis of substernal adenomatous goiter. Macroscopically, the material obtained presented globose aspect, with brown and white areas permeated by maroon spotlights, weighing $250 \mathrm{~g}$, with smooth and ascularized grayish capsule, measuring 9x8x7.5 cm. The diagnosis was follicular hyperplasia with goiter. After partial thyroidectomy, the patient was not subjected to any other type of treatment or control of the lesion.

The clinical condition of the patient was debilitated with general commitment of vital functions, somber prognosis, and there were reports about the presence of other metastatic tumors discovered after the diagnosis of metastasis to mandible. However, many

Figure 3. Procedure of Puncture to Collect and Evaluate the Internal Material.
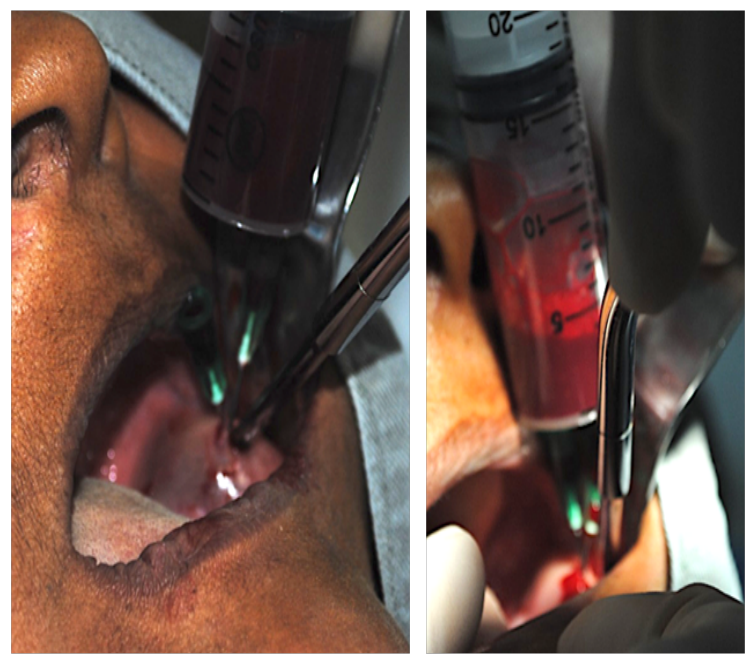

Figure 4. Surgical Management for Removal of Pathology.
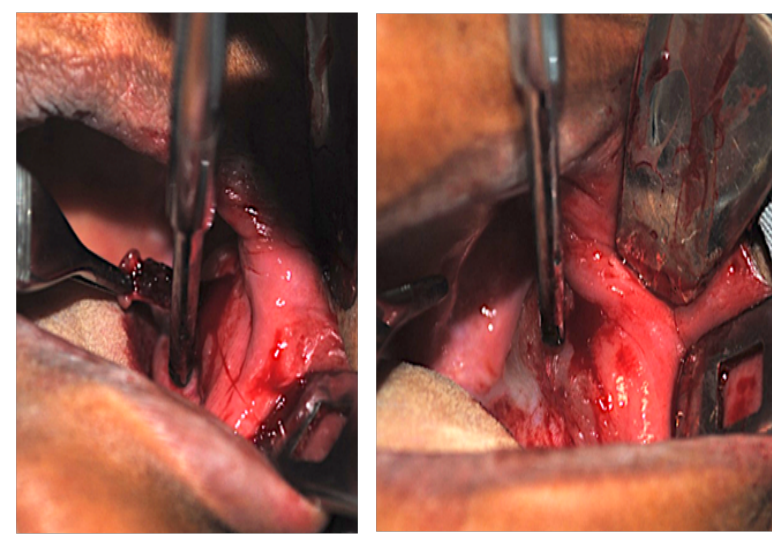
Figure 5. 100x increase, Demonstrates Follicles of varying Sizes.

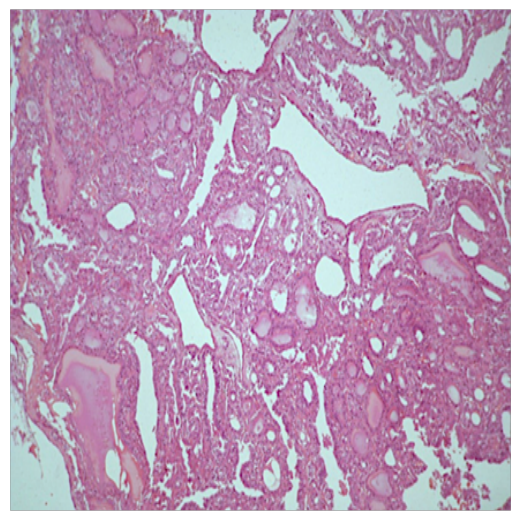

Figure 6. -400x increase, Demonstrates Follicles with Cytological atypia and Central Colloid.

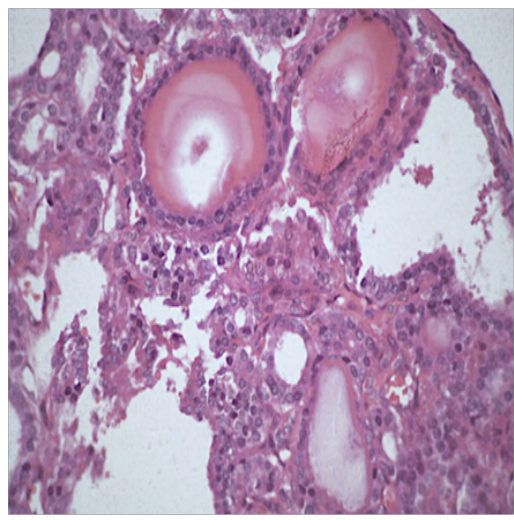

Figura 7. -400x increase, Present in Details Follicles with Cytological atypia Adjacent to Pseudo - Capsule and Desmoplastic Stromal.

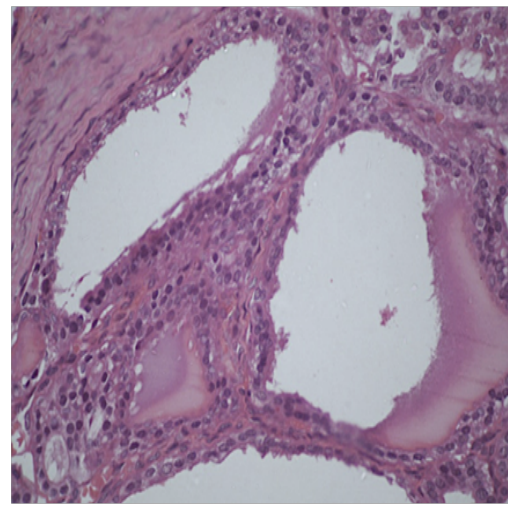

measures were implemented to allow a better patient survival, but she died due to pathology present in a very advanced stage and all management conducted was unsatisfactory.

\section{Discussion}

In survey of metastatic tumors diagnosed between 1989 and 2005 , the authors found only 4 located in maxilla, representing $1 \%$ of total lesions confirmed histologically. Among these, three were located in the mandible and one in the maxilla, two were originated from the thyroid gland, one from the esophagus and one from the liver [9-14].

Primary thyroid tumors present an annual incidence of $0.5-10$ cases per 100,000, in which the anaplastic thyroid carcinoma (ATC) comprises in 1-2\% of all primary tumors of the thyroid.
Metastasis of thyroid carcinoma in mandible affect mainly the sixth and seventh decade of life according to the case reports in the literature [5, 15-17].

The female gender is more affected by pathology, agreeing with the findings in research and case reports, only 2 cases are reported in the masculine gender [3].

The metastases in mandible are more frequent, predominantly in premolar and molar region, than in the maxilla, the active red marrow present in mandible promotes the establishment and growth of metastases. It also explains the low number of cases of metastasis in maxillary bone because of the less concentration of red marrow in these structures. However, the jaws are not routinely examined in autopsies, thus, the true frequency of thyroid metastases in jaw can be higher [18]. 
The patient presented bicortical expansion of the body of the mandible, the literature shows that radiographically, the lesions are undefined and may present themselves as osteolytic or radiolucent ones, withill-defined margins that in metastases of breast, lung and prostate, may present sclerotic aspect, they may also present osteoblastic, radiopaque ormist aspect [19].

In the case reported the metastatic lesion in the body of the mandible was decisive in the diagnosis of follicular thyroid adenocarcinoma, being the first metastatic lesion discovered, indicating the presence of malignancy in the primary site [20].

\section{Conclusion}

The performance of biopsy in maxillomandibular complex lesionsis often the initial diagnostic tool for Metastases of primary lesions. In the case presented, the patient had removed a benign lesion on thyroid and she was not subjected to monitoring, thus, there were malignancy of the frame that metastasized to mandible. The late diagnosis of the condition has led to a somber prognosis; it was also due to the pathophysiology of primary tumor.

\section{References}

[1]. Villaret AB, Piazza C, Peretti G, Calabrese L, Ansarin M, et al., (2007) Multicentric Prospective Study on the Prevalence of Sublevel IIB Metastases in Head and Neck Cancer. Arch Otolaryngol Head Neck Surg. 133(9): 897903.

[2]. Ostrosky A, Mareso EA, Klurfan FJ, Gonzalez MJ (2003) Mandibular metastasis of follicular thyroid carcinoma. Med Oral. 8: 224-7.

[3]. Antunes AA, Antunes AP (2008) Gastrointestinal bone metastases: a retrospective study of 10 cases. Rev Bras Otorrinolaringol. 74(4): 561-565.

[4]. Raubenheimer EJ, Noffke CEE (2006) Pathogenesis of bone metastasis: a review J Oral Pathol Med. 35(3): 129-35.

[5]. Tamiolakis D, Tsamis I, Thomaidis V, Lambropoulou M, Alexiadis G, et al., (2007) Jaw bone metastases: four cases. Acta Dermatovenerol Alp Pannonica Adriat. 16(1): 21-25.

[6]. Pruckmayer M, Glaser C, Marosi C, Leitha T (1998) Mandibular pain as the leading clinical symptom for metastatic disease: Nine cases and review of the literature. Annals of Oncology. 9(5): 559-564.

[7]. Bodner L, Sion-Vardy N, Geffen DB, Nash M (2006) Metastatic tumors to the jaws: A report of eight new cases. Med Oral Patol Oral Cir Bucal. 11(22): 132-135.

[8]. Ismail SB, Abraham MT, Zaini ZB, Yaacob HB, Zain RB (2009) Metastatic follicular thyroid carcinoma to the mandible: a case report. Cases J. 2: 6533

[9]. Algahtani M, Alqudah M, Alshehri S, Binahmed A, Sándor GK (2009) Pathologic Fracture of the Mandible Caused by Metastatic Follicular Thyroid Carcinoma. JCDA. 75(6): 457-460.

[10]. Hoie J, Stenwig AE, Kullmann G, Lindegaard M (1998) Distant metastases in papillary thyroid carcinoma: A review of 91 patients. Indian J Cancer. 61(1): 1-6.

[11]. Pasupula AP, Dorankula SP, Thokala MR, Kumar MP (2012) Metastatic follicular thyroid carcinoma to the mandible. Indian J Dent Res. 23(6): 843.

[12]. Ravi PSM, Verma S, Gill N, Malik V (2012) Multiple gingival metastasis of adenocarcinoma of the lung. Indian J Dent Res. 23(4): 558-9.

[13]. Pozzi EC, Altermatt HJ, Rees TD, Bornstein MM (2008) Exophytic mass of the gingiva as the first manifestation of metastatic pulmonary adenocarcinoma. J Periodontol. 79(1): 187-91.

[14]. Kathuria K, Jambhekar NA, Pramesh CS, George K, Desai SS (2013) A clinicopathologic analysis of 88 lung resections of suspected metastatic carcinomas with proven primaries. Indian J Cancer. 50(4): 356-60.

[15]. Germain MA, Marandas P, Leridant AM, Domenge C, Julieron M, et al., (1998) Isolated mandibular metastasis of cancer of the thyroid. Mandibulectomy and reconstruction using a free vascularized peroneal graft. Rev Stomatol Chir Maxillofac. 98(6): 371-4.

[16]. Stulík J, Kozák J, Sebesta P, Vyskocil T, Kryl J, et al., (2007) Total spondylectomy of C2: a new surgical technique. Acta Chir Orthop Traumatol Cech. 74(2): 79-90.

[17]. Nawale KK, Vyas M, Kane S, Patil A (2016) Metastatic tumors in the jaw bones: A retrospective clinicopathological study of 12 cases at Tertiary Cancer Center. J Oral Maxillofac Pathol. 20(2): 252-5.

[18]. Draper BW, Precious DS, Priddy RW, Byrd DL (1979) Clinicopathological conference. Case 29, part 2. Follicular thyroid carcinoma metastatic to the mandible. J Oral Surg. 37(10): 736-9.

[19]. Vazifeh LM, Irani S, Rajati M, Memar B (2013) Mandibular metastasis from follicular thyroid carcinoma: a rare case after twelve years. Arch Iran Med. 16(9): 557-9.

[20]. Nishikawa H, Nakashiro K, Sumida T, Sugita A, Hamakawa H (2010) Mandibular osteoblastic metastasis of poorly differentiated carcinoma of the thyroidgland. Int J Oral Maxillofac Surg. 39(3): 301-4. 